Section Editor

Mitchell S.V. Elkind,

MD, MS

\title{
Neurosyphilis presenting as mesial temporal encephalitis
}

CLINICAL PEARL Neurosyphilis can present with a myriad of signs and symptoms. Mesial temporal lobe inflammation is a rare and under-recognized presentation of neurosyphilis that may mimic viral or limbic encephalitis. Concomitant HIV infection is common and may change the presentation of neurosyphilis.

CASE REPORT A 51-year-old right-handed Caucasian man presented with a 3-week history of personality changes with deteriorating social interactions, progressive forgetfulness, and apathy. He complained of a new-onset worsening headache described as "a sledgehammer hitting both sides" of his head. The patient denied constitutional symptoms and his prior medical history was unremarkable. He became disheveled, confused, and unable to care for his family and a successful business he had built. In the days leading to the patient's medical evaluation, he was delusional and appeared to be experiencing visual hallucinations.

On admission, the patient was found to have normal vital signs and general physical examination. Neurologic examination revealed dysphoric mood, decreased attention, and disorientation to time and place. His speech was fluent and he was able to name, repeat, and follow 3-step commands. The patient's score on the Montreal Cognitive Assessment examination was 17/30, primarily due to impairments in recall, visuospatial, and executive functions. He frequently confabulated and claimed to have known each of the medical staff at one point in his life. His pupils were equal, round, and reactive to light and accommodation. The rest of his cranial nerves and motor and sensory examinations were intact. Romberg test was negative. Initial laboratory tests were remarkable only for mild anemia (hemoglobin $12.6 \mathrm{~g} / \mathrm{dL}$ ) and hyponatremia (sodium $133 \mathrm{mmol} / \mathrm{L}$ ). Brain MRI revealed abnormal fluid-attenuated inversion recovery (FLAIR) and T2 signal within the bilateral frontal and mesial temporal lobes, raising a concern for encephalitis (figure 1). He was started on IV acyclovir and CSF analysis showed a glucose level of $48 \mathrm{mg} / \mathrm{dL}$, erythrocytes $3 / \mu \mathrm{L}$, leukocytes $220 / \mu \mathrm{L}$ (lymphocytes $69 \%$, neutrophils $11 \%$, monocytes $20 \%$ ), and CSF protein of $205 \mathrm{mg} / \mathrm{dL}$. EEG demonstrated focal left anterior temporal lobe slow waves. CSF herpes simplex virus (HSV), West Nile virus, and other infectious testing were negative. Malignancy workup including CSF cytology was also negative. Paraneoplastic antibodies were absent. The patient tested positive for syphilis as evidenced by reactive serum rapid plasma reagent test (titer, 1:64) and CSF Venereal Disease Research Laboratory (VDRL) test (titer 1:16). Acyclovir was discontinued and the patient was started on penicillin $\mathrm{G}$ for a total of 21 days. His fluorescent treponemal antibody-absorption test also came back positive as a confirmatory test for neurosyphilis. Further serologic workup revealed that he was HIV-positive with a CD4-lymphocyte count of 396.

The patient's hospital stay was complicated by a series of generalized tonic-clonic seizures and status epilepticus requiring intubation and intensive care unit monitoring. Repeat EEG showed independent left and right temporal periodic lateralized epileptiform discharges. His seizures were treated successfully with phenytoin. Ten days into the course of antibiotic therapy, a repeat lumbar puncture showed marked decrease in the amount of CSF protein and leukocytosis (protein of $80 \mathrm{mg} / \mathrm{dL}$ from $205 \mathrm{mg} / \mathrm{dL}$ and leukocytes of $34 / \mu \mathrm{L}$ from $220 / \mu \mathrm{L}$ ). The patient's mental status improved considerably but he continued to have short-term memory impairment and required frequent redirection. Prior to his discharge, he was started on highly active antiretroviral therapy and transferred to a skilled nursing facility.

He was seen in the outpatient setting 6 weeks later. His speech was fluent and he was able to hold a complex conversation. He continued to demonstrate severe short-term memory impairment and required frequent reorientation. Phenytoin was successfully transitioned to levetiracetam for long-term seizure prophylaxis. Repeat MRI of the brain performed a month after his hospital discharge showed improvement of the T2 and FLAIR signal abnormality within the frontal and mesial temporal lobes. However, there was progression of atrophy of the mesial temporal lobes compared to the initial study (figure 2), suggesting irreversible damage.

DISCUSSION Neurosyphilis refers to infection of the CNS by the spirochete Treponema pallidum. This can occur anytime between the initial inoculation and the late stage of tertiary syphilis. Early neurosyphilis may be latent and asymptomatic or may include

From the Department of Neurology, Thomas Jefferson University Hospital, Philadelphia, PA.

Go to Neurology.org for full disclosures. Disclosures deemed relevant by the authors, if any, are provided at the end of this article. 
Figure 1 Initial brain MRI

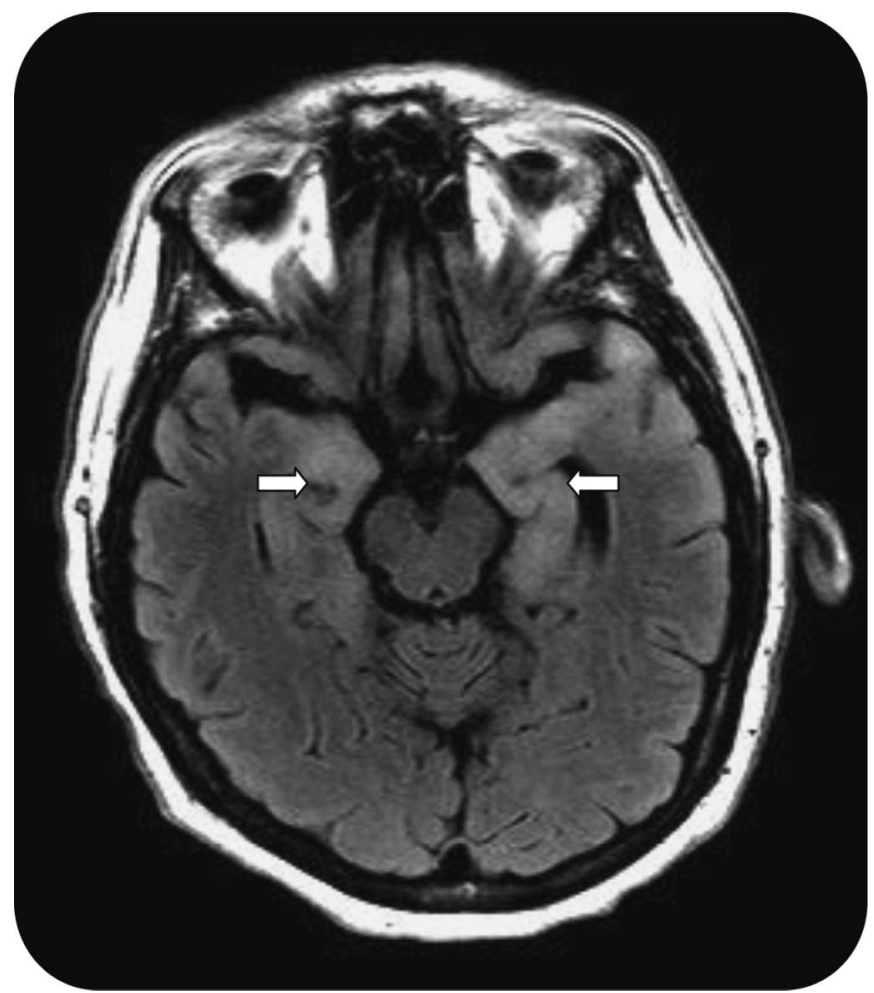

Abnormal T2 and fluid-attenuated inversion recovery signal within the bilateral frontal and mesial temporal lobes (arrows). There is also notable atrophy of the mesial temporal lobes.

\section{Figure 2 Follow-up brain MRI}

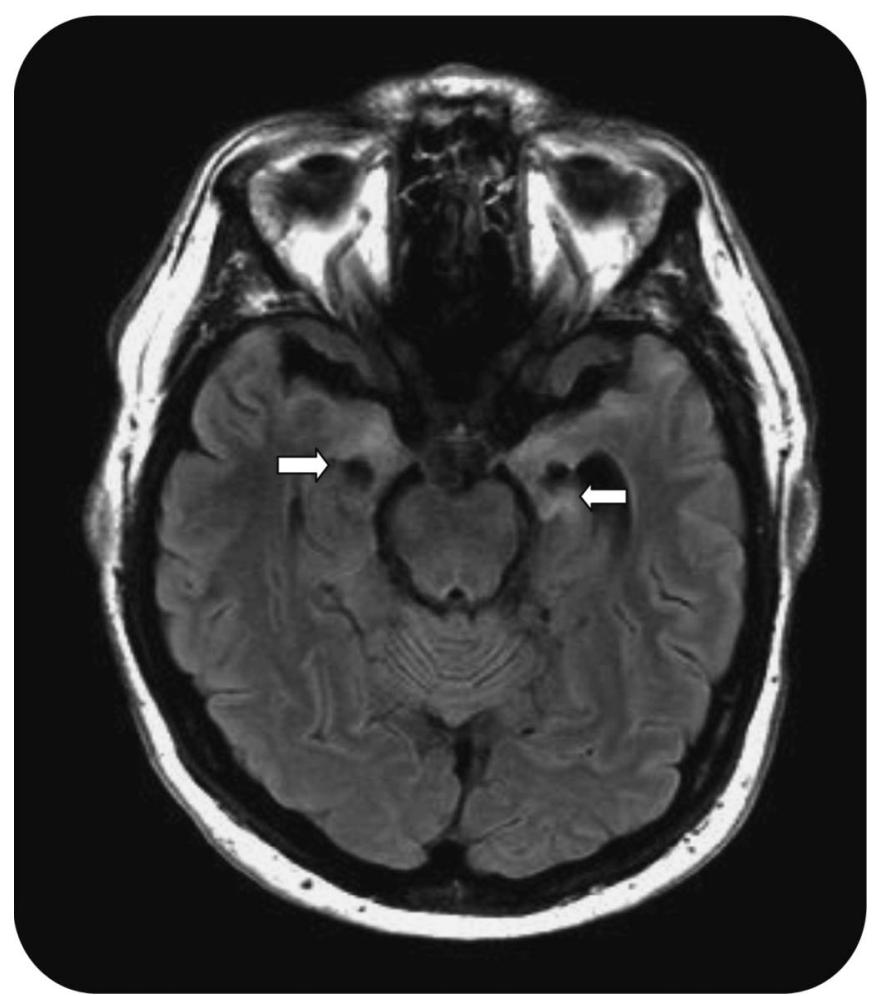

Improvement in the T2 and fluid-attenuated inversion recovery signal abnormality within the frontal and medial temporal lobes compared to the prior study. Progression of mesial temporal lobe atrophy is also seen. meningitis, strokes, vertigo, optic neuritis, or uveitis. It typically occurs within the first year after acquisition of the infection. The pathophysiology involves an acute meningovascular and ocular inflammation resembling other infectious, inflammatory, or autoimmune processes of the CNS. Late or tertiary neurosyphilis is characterized by chronic infection of the brain parenchyma or the posterior columns of the spinal cord. This may lead to forgetfulness and personality changes known as general paresis, and impaired proprioception and gait imbalance termed tabes dorsalis. ${ }^{1}$

General paresis typically has a progressive course and presents many years after a treponemal infection. It is unclear when our patient was initially exposed to syphilis. To his wife's knowledge, he had engaged in promiscuous homosexual intercourse 6-8 months prior to his presentation. Furthermore, general paresis is not known to be associated with mesial temporal lobe inflammation mimicking that of herpes encephalitis and paraneoplastic limbic encephalitis. This atypical presentation of neurosyphilis along with the unknown time of infection make it difficult to classify under the classic stages of neurosyphilis. It was previously believed that parenchymal involvement occurs in the late tertiary stages of neurosyphilis after 3-15 years of the initial infection. ${ }^{1}$

Although untreated HIV may spread to the CNS and cause insidious cognitive and behavioral changes, it is unknown to cause destructive temporal lobe lesions and seizures. The absence of other infectious and inflammatory agents and the rapid improvement on brain MRI (figure 2) following antibiotics point toward an aggressive treponemal CNS infection as the main culprit. Mesial temporal lobe involvement secondary to neurosyphilis has already been described in the literature. $^{2-5}$ It is unclear what causes the T2 hyperintensity changes in the mesial temporal lobes of those patients. It is believed that the marked meningovascular inflammation causes vasogenic, cytotoxic, and interstitial edema to occur. Also, the infection-induced small-vessel ischemic changes cause gliosis to ensue. ${ }^{2}$ To our knowledge, none of the other similar cases ${ }^{2-5}$ with neurosyphilis were also found to have HIV and it is unclear what role this concomitant infection may have played, if any.

The association between neurosyphilis and HIV infection is an important one because both can be a consequence of promiscuous sexual behavior. It is thought that the genito-ulcerative chancres seen in syphilis increase the risk for viral entry during unprotected sexual intercourse. Also, the increased concentration of $\mathrm{T}$ cells at the site of the chancres augments the possibility of the HIV virus infecting and replicating in the host cell. ${ }^{1}$ In patients with concomitant HIV infection, neurosyphilis may progress in an aggressive and often atypical manner. ${ }^{1,6}$ It has been suggested that the course of syphilis in HIV-infected men may be altered as a result of potentiating effects of HIV on the $T$ pallidum 
infection. ${ }^{7,6}$ According to the Centers for Disease Control and Prevention treatment guidelines, it is recommended that HIV-infected patients with neurosyphilis undergo follow-up CSF examination every 3-6 months until the cell count normalizes. ${ }^{7,8}$ One study found that HIV-infected patients with neurosyphilis are at least 2.5 times less likely to normalize the CSFVDRL reactivity after penicillin treatment. The risk is even higher if the CD4+ T-cell count is $<200$ cells/ $\mu \mathrm{L} .{ }^{9}$ The estimated incidence of symptomatic neurosyphilis among HIV-infected persons with early syphilis was found to be $3-4$ times higher $(2.1 \%$ vs $0.6 \%)$ as compared with HIV-negative persons. ${ }^{10}$

Although believed to be rare, neurosyphilis should be part of the initial diagnostic workup of an atypical and rapidly progressive dementia. It should be considered in the differential diagnosis of diseases mimicking HSV and limbic encephalitides. Clinical outcome of patients diagnosed with this condition varies but early recognition and treatment are crucial to prevent further cognitive decline and morbidity.

\section{AUTHOR CONTRIBUTIONS}

Kader T. AbdeleRahman, MD, treated the patient in this case report and wrote the presented case report. Dolores D. Santamaria, MD, treated the patient in this case report and provided references for the case report. Goran Rakocevic, MD, treated the patient in this case report, provided references, and made several revisions to the case report.

\section{DISCLOSURE}

The authors report no disclosures relevant to the manuscript. Go to Neurology.org for full disclosures.

\section{REFERENCES}

1. Tyler KL, Martin JB. Neurosyphilis. In: Tyler KL, Martin JB, ed. Infectious Diseases of the Central Nervous System, ch 11. Philadelphia: FA Davis; 1993:250.

2. Bash S, Hathout GM, Cohen S. Mesiotemporal T2-weighted hyperintensity: neurosyphilis mimicking herpes encephalitis. AJNR Am J Neuroradiol 2001;22:314.

3. Denays R, Collier A, Rubinstein M, Atsama P. A 51 year-old woman with disorientation and amnesia: case report. Lancet 1999;354:1786.

4. Angus F, Maysuria H, Bryan CS. Neurosyphilis mimicking herpes simplex encephalitis. J S C Med Assoc 1998;94: 315-317.

5. Szilak I, Marty F, Helft J, Soeiro R. Neurosyphilis presenting as herpes simplex encephalitis. Clin Infect Dis 2001;32: 1108-1109.

6. Johns DR, Tierney M, Felsenstein D. Alteration in the natural history of neurosyphilis by concurrent infection with the human immunodeficiency virus. N Engl J Med 1987;316: 1569-1572.

7. Musher DM, Hamill RJ, Baughn RE. Effect of human immunodeficiency virus (HIV) infection on the course of syphilis and on the response to treatment. Ann Intern Med 1990;113: 872-881.

8. Workowski KA, Berman SM. Sexually transmitted diseases treatment guidelines, 2006. MMWR Recomm Rep 2006; 55:1-94.

9. Marra CM, Maxwell CL, Tantalo L, et al. Normalization of cerebrospinal fluid abnormalities after neurosyphilis therapy: does HIV status matter? Clin Infect Dis 2004; 38:1001-1006.

10. Taylor MM, Aynalem G, Olea LM, He P, Smith LV, Kerndt PR. A consequence of the syphilis epidemic among men who have sex with men (MSM): neurosyphilis in Los Angeles, 2001-2004. Sex Transm Dis 2008;35:430-434. 


\section{Neurology}

\section{Pearls \& Oy-sters: Neurosyphilis presenting as mesial temporal encephalitis}

Kader T. AbdeleRahman, Dolores D. Santamaria and Goran Rakocevic

Neurology 2012;79;e206-e208

DOI 10.1212/WNL.0b013e318278b5a1

This information is current as of December 10, 2012

\section{Updated Information \&} Services

References

Citations

Subspecialty Collections

Permissions \& Licensing

Reprints including high resolution figures, can be found at: http://n.neurology.org/content/79/24/e206.full

This article cites 8 articles, 0 of which you can access for free at: http://n.neurology.org/content/79/24/e206.full\#ref-list-1

This article has been cited by 1 HighWire-hosted articles: http://n.neurology.org/content/79/24/e206.full\#\#otherarticles

This article, along with others on similar topics, appears in the following collection(s):

\section{All Cognitive Disorders/Dementia}

http://n.neurology.org/cgi/collection/all_cognitive_disorders_dementia Bacterial infections

http://n.neurology.org/cgi/collection/bacterial_infections

Encephalitis

http://n.neurology.org/cgi/collection/encephalitis

HIV

http://n.neurology.org/cgi/collection/hiv

\section{HIV dementia}

http://n.neurology.org/cgi/collection/hiv_dementia

Information about reproducing this article in parts (figures,tables) or in its entirety can be found online at:

http://www.neurology.org/about/about_the_journal\#permissions

Information about ordering reprints can be found online:

http://n.neurology.org/subscribers/advertise

Neurology ${ }^{\circledR}$ is the official journal of the American Academy of Neurology. Published continuously since 1951 , it is now a weekly with 48 issues per year. Copyright (C) 2012 American Academy of Neurology. All rights reserved. Print ISSN: 0028-3878. Online ISSN: 1526-632X.

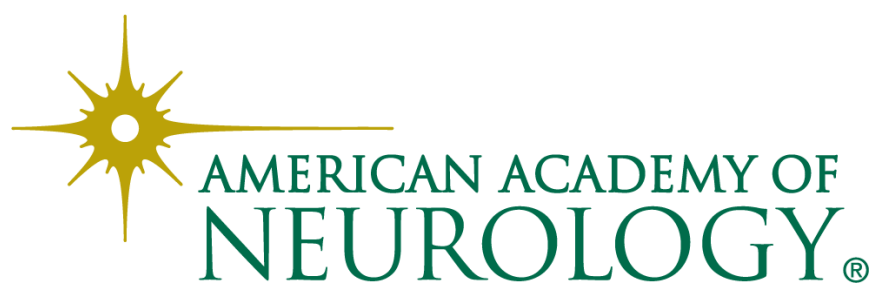

